\title{
ERKLÄRUNG DER ABKÜRZUNGEN.
}

AK. Altkönigliche Sammlungen, welche vor Errichtung des Museums in der Kunstkammer des königlichen Schlosses zu Berlin sich befanden.

1T. Antikentempel zu Potsdam.

Bair. Sammlungen, welche von I. K. H. der Frau Markgräfin von Baireuth in Italien veranstaltet wurden und durch Vermächtnifs an Friedrich den Grofsen übergingen.

Barth. Bartholdysche Sammlung S.142 Anm. 3.

BS. Königliches Schlofs zu Berlin.

BM. Ankaufe des Hrn. Generallieutenants von Minutoli Exc. aus der Borgiaschen Sammlung.

Ch. oder Charl. Königliches Schlofs zu Charlottenburg.

D. Durchmesser.

DM. Dorowsche durch Hrn. Magnus vermehrte Sammlung S.142.

EEG. Etruskische Erwerbungen des Prof. Gerhard.

Gr. M. Griechischer Marmor.

II. Höhe.

K. Kollersche Sammlung S. 142.

$K K$. Kunstkammer des königlichen Schlosses zu Berlin.

M. Marmor.

NEG.' Neapler Erwerbungen des Prof. Gerhard.

NEI. Neapler Erwerbungen des königl. wirkl. Geheimen Raths Hrn. Grafen von Ingenheim S. 142 Anm. 1.

NGr. Natürliche Gröfse.

$P$. oder Pol. Polignacsche Sammlung.

Par. M. Parischer Marmor.

PMS. Marmorschlofs zu Potsdam.

PNS. Neues Schlofs ebendaselbst.

$R E B i$. Römische Erwerbungen des königl. sächsischen Agenten Hofrath Bianconi. Vgl. S. 11 Anm. 4.

$R E B$. Römische Erwerbungen des königl. Gesandten zu Rom Herrn Geh. Leg. R. Bunsen. 
REBM. oder REM. s. BM.

$R E E$. Römische Erwerbungen durch Hrn. von Erdmannsdorf im Jahr 1791 vermittelt.

REG. Römische Erwerbungen des Prof. Gerhard.

REI. Römische Erwerbungen des königl. wirklichen Geheimen Raths Grafen von Ingenheim.

SS. Königliches Schlofs zu Sanssouci.

$S S B$. Bildergallerie ebendaselbst.

SSG. Garten ebendaselbst.

SSJ. Jaspissaal ebendaselbst.

St. Statue.

UH. Unbekannte Herkunft.

$V d M$. Villa di Mario S. 10 Anm. 5. 